\title{
Web-based Services-Oriented Software Lifecycle Management
}

\author{
Rajeshwar Vayyavur \\ (IEEE Senior Member) \\ Public Consulting Group Inc. \\ 148 State Street \\ Boston, MA 02109, USA
}

\begin{abstract}
There are various processes in the project management software that helps in the system inter-process communication between the remote teams and distributed teams. Web-based services oriented can vastly improve project management efficiency of the software lifecycle management. It's something that heightens the control and visibility of the application development lifecycle that offers suitable control over the entire development process that runs from the management stage to the development stage.
\end{abstract}

\section{General Terms}

Cloud, Web-based services-oriented software lifecycle

\section{Keywords}

Web, Cloud, Agile, Software, Application, Service, Lifecycle, Development

\section{INTRODUCTION}

Failure of manageability, as well as creeping projects scope, are among the key challenges plaguing IT firms in the current times. Not only may these problems be technical and challenging, they have the potential of developing deadly to the ultimate objectives of the company. For the purpose of competing, it is essential to take out uncertainty with business technologies that improve definition, scope, and purpose. Web-based services-oriented software life cycle management solution offers the team suitable time insight into project requirements. Above that, it facilitates the inevitable changes in the firm of the scope that cross the boundaries of the distributed teams. The visibility helps members of the team to share in project expectations from the outset. Hence developing an alignment of thinking that leads to managed control and higher productivity of the development process [1].

The aim of project management software is to create and design a product that delivered on time. It must be produced with the capabilities expected by client and within the allocated budget. Web-based services-oriented software management lifecycle is a properly managed project, which has managed set of goals, objectives, uses a clear and communicated aspect, plus it has progressed that effectively controls the entire population. Resources required in the management concept are used to produce the required product. Research shows that a project usually entails various processes that highlight daily activities of the forming the project framework and developing the entire project for the organization [3].

\section{DISCUSSION}

Web-based services-oriented software lifecycle management gives end users a platform that allows them to move into the future without any concept of abandoning the past something that offers interoperability something that is fundamental towards the application lifecycle. The issue of globalization for most firms in the current times around the clock, development sounds, and nonstop design comes in a better manner. It's something precisely on the point since the reality seems to have various multiples of aspects that have failed and creates a system that is reliable to the organization. The first element is that one needs to integrate environment from the management change as well as configuration the required aspects. System in that aspect need to be designed so as to provide visibility towards the development process one that will allow the management team to maintain the control of the application lifecycle [8].

Web-based services-oriented software lifecycle management helps to collect the information on different angles in respect to software development lifecycle. Various elements used in the product development or during the software design process must define in accordance. The aspect gives of various levels of the software. The aspect helps to monitor the process of the software lifecycle management and gives the reports in a suitable way. In that manner, it helps maintain the details of the developer and client interaction as all the documentation work is completed by the client. The software development team who operates on the product ensures that proper elements are put to ensure that the ideal or desired results. Information updating is carried out by those authorized by the company. These are individuals who are in contact with the end user as well as with the development team [11].

The selected project manager can manage all his developers' activities, and the client will monitor the progress of the product development. It's a focus that will ensure these activities are well defined, and no time or money goes waste during these aspects. Client who offers the product to be established by the company has the responsibility to view the documentation needed. Tight schedule gives a platform on the ideal status plus the reports on the process towards the project development and establishment. As the software established the ideal process for its design, the situation might be extended to the other concepts where it offers various elements that give solutions [2].

\subsection{Service Life Management}

Procedures, standards, and policies define a good platform in which care taken to implement concepts. In any time when one firm develops a web based services software lifecycle management structure plus it creates a critical to get the buy- 
in aspect. It develops from anyone who wishes to operate or work with the situation. The aim at such a concept is to assist plus ensure that better, and new directives are not too challenging to follow. Elements of protecting and preventing workers to the concept of reverting back to the old practices that call for the simple system that may not support new approaches or technologies [7].

Service oriented lifecycle management plays a vital role since it does focus on the concept of implementing the decision rights. It also establishes policies and processes that allow proper govern service, management, deployment, and development, plus sit focuses towards the concept of automating the key processes and monitoring the ideal results. The use of a well-defined infrastructure gives an end to end process for developing and managing services in the enterprise. Research shows that firms may extend their services oriented management platform to those parties involved in delivery and service creation, irrespective of any worker's office location, time zone, and nation. Suppliers as well as business partners that have different firm structures, technologies, and processes might also develop into the fold. Players from firm analysts to testers can validate that the main services they are managing, deploying, assembling, and modeling do remain aligned with the enterprise needs [10].

In ideal concepts, service lifecycle management might allow the user complete the project in a better way through the establishment of automated processes and procedures that ensures that defined project is growing. Success plays a vital role and it assure business units that it operates in a safe aspect, hence suitable to share their once proprietary services and reuse enterprise assets. Even in a situation where the expanded concepts apply, assets to various firms units and outside partners allows the entire concept to operate effectively. Through mining existing data investments and software to design new services. Through encouraging widespread, it allows the use of the assets across the organizations may help realize benefits. These benefits may be organizational, process flexibility, and greater productivity while lowering systems delivery costs and software [1].

\subsection{Elements of Cloud Service Integration and Management}

The functional elements linked to the cloud manageability and integration is shown below in the Figure-1. Integration elements (in the center of the Figure 1 gives the purpose to guarantee architectural compatibility as well as inter-working of the planned cloud services as well as other applications that are critical. The aspect comprises two major integral elements which are interoperability and portability. Cloud portability refers that workloads have the potential to move around clouds and providers. It means the migration of the entire application configures across clouds. The migration of live related deployments across heterogeneous clouds operates effectively in a suitable manner [11]. Cloud interoperability gives the possibility to apply and seamlessly use cloud services from distinctly separate, as well as independent cloud service clouds and providers. Basing that there exist different ties in the cloud stack poses different requirements with respect to interoperability, the aspect in cloud sourcing approached from the perspective of the defined concept.

\subsection{Cloud Service Management}

Cloud service management entails all of the service related functions necessary for the operation plus management of cloud services that needs to be applied by cloud developers. The aspect of cloud service management might be defined based on the perspective of well-established concepts. Rapid resource provision is the first technical dimensions which are a cloud-based application. The application needs to have the capacity so as to handle various kinds of demands that develop upon it at run-time. With that requirement for additional servers that needs to be provisioned as well as configured dynamically through an automated provisioning engine [8].

\subsubsection{Configuration:}

It's a technical dimension that develops out the real configurations. The approach is ideal in the web based services software orientation management lifecycle that reshapes the cloud environment. With such a move, it meets the needs of the requested services that focus on the pull model. It's a suitable element that may have and operate with an application system and stack configuration plus other aspects within the runtime configuration and the scaling rules management. Most firms fail to operate their projects due to poor ways their use when working on their projects on configuration [4].

\subsubsection{Troubleshooting and Monitoring:}

During a situation where a web based services-oriented software lifecycle management is running, agile resources need to be monitored for bottlenecks plus for user defined thresholds something that exceed the prescribed limits. It identifies any existence of potential problems before they manifest. Research has it that cloud sourcing for testing and dynamic logging must exist to allow a better and suitable application [5]

\subsubsection{Tracking and Auditing:}

In the aspect of auditing, it offers the concept of the ability to give relevant to parties' aspects on a single platform of thread and work of execution across multiple inter-linked cloud resources. All services that are cloud-related requires proper audit and measurements that might use in the comparison against SLA stipulations. Any level of tracking requires someone to understand measurements, hence it can be applied to compare. It allows parties concerned in tracking that helps understand where the workload ran when, the time it takes matters. The relevant elements offer an audit trail that exists in for use whenever operations management entails [13].

\subsection{Development Lifecycle Management}

The figure -2 below offers a complete as well as a tentative solution of cloud agile application development thoroughly develops the management of software project's simple. The lifecycle management facilitates firms with several development teams something that supports $\mathrm{AD}$ economically and quickly through an extensive series of features and functionalities. The platform gives the ability in the overwhelming the challenges of both $\mathrm{AD}$ and $\mathrm{CC}$ by performing cloud all the way. With the automation concept, processes workflow is developed smoothly towards avoiding people intrusion. It helps make processes well organized, fully protected, sustained, error-free, and controlled in accordance [10].

The concept of team collaboration helps to get out that the codes, documents, wiki content, and artifacts plus the threads are well hosted on the cloud based on the limits established. Enterprise search infrastructure helps to design the wellknown and distributed concept to a better defined and correspondent activity. Social architecture use for tracking and coding artifacts; hence it offers organizational limits and cooperation in geographical transversely [6]. Another relevant 
aspect is the user tool integration. Within the agile application development lifecycle management, user tool integration creates the consumptions of assembled plus test servers that may be initiated by the developers. The integration of data from various data servers might be permitted to the end users. It's something that helps the lifecycle management to give security plus the governance something that is particularly relevant in the cloud-based platforms [11].

\subsection{Implementing Service Lifecycle Management}

\subsubsection{Model: from approval to design}

At the model stage, firm validate, analyze plus assess planned service development projects. It begins with the annual planning for portfolio and project management. The aspect develops at the end of the business financial year. Projects requested made prioritized within the established cost-benefit analysis for the concept that related to software management. In this case, IT executives operate in a way that eliminates duplication as well as overlap between readjust and projects so as to align the projects related concepts of the organization. The concept also helps in the measuring and monitoring of actual performance so as to have the project that is not deviating from the estimates that are within the required platform. The step also encompasses analyzing and modeling business processes thus ensuring that firm model to allow the team analyzes current process during the software design [8].

\subsubsection{Assemble: from design to test}

At the assembly stage, designers of the web based servicesoriented software management lifecycle, developers established a together re-useable service concepts as a way to develop service-oriented application for the purpose of integrating and automating business processes. The refining the service architecture is the second step developed in the service lifecycle activities on a given system design. When models activities complete in the lifecycle, it's ideal to refine the service model so as to flesh out the architecture that comprises actual business, frameworks, and services processes. At this level, software designers conduct service lifecycle activities that encompass service, architecture design, testing, and process development. During lifecycle management concept, testing for reuse and use in the situation allows to provide that a new system helps to operate in accordance. Testing of developers is carried out in a different manner after all the assembling the composite application is ideal [9].

\subsubsection{Deploy: from test to the service environment}

When a service term as fit for use, new challenges develop into play. These are the rules that help in the governance of the software as well as to parties that are in the expertise and external parties. It is a recommendation for the firm during service deployment to support all critical aspects that require for the software management. IT staff within the company uses various elements such as metadata in the process of evaluating whether software services deployed are successful plus observe service usage patterns. During the software management phase, service data that exists in registers may be reconciled with the real monitoring data collected from production systems. It helps to establish whether there exist services in the deployment that might not be in the platform or those that are not through the established management process used for the web-based services [1].

\subsubsection{Manage: from the operation to retirement}

Once web based services are in production, companies need to manage them so as to help service quality, adherence, compliance, and security to service level objectives. It's an approach that focuses on matters of firm delivery on proper service quality on the software adherence elements. Change management continues to be relevant plus helps in greater flexibility that gives services concept to ensure every concept operates in accordance. The higher degree that relates to flexibility during service provision benefits the company in ensuring proper and ideal IT operations. It has higher tracking dependencies as well as changes that are well defined. So as to avoid downtime plus meet service level commitments, companies need to monitor performance through the service lifecycle [8].

\section{CONCLUSION}

The introduction of Web-based services-oriented software lifecycle management into an IT firm demands policy and structural changes. It's something that develops new demands for alignment among various processes that has different areas of the firm. The service lifecycle management aspect may help companies manage the governance policies and other aspects that need in the delivery of business benefits. Webbased services-oriented software life cycle management solution offers the team a better and suitable real-time insight into project requirements. It facilitates the inevitable changes of the scope that cross the boundaries of the distributed teams.

Future study on web based services attracts sound platforms with prime international forum for both industrial practitioners. It should aim at exchanging the latest fundamentals advances in the state of the art plus practice of web related services; hence identify areas of great concern that are emerging. Since web based services have a high level of platform, further research on this area will focus to establish advance in large international professional forum in respect to the needs of the organization system.

\section{FIGURES}

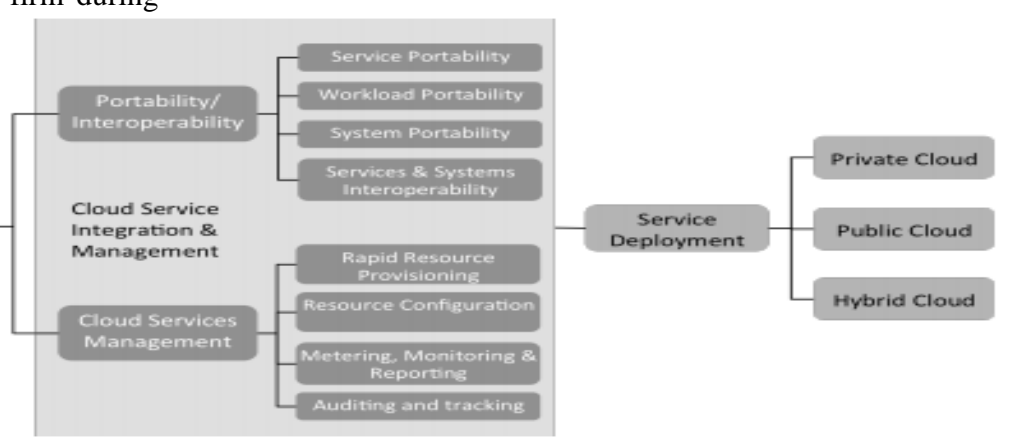

Figure 1: Elements of Cloud Service Integration and Management 
Note: "Design Science Research: The Case of the IT Capability Maturity Framework (IT CMF), the Electronic
Journal of Business Research Methods" Carcary M (2011), 9 (2), pp. $109-118$
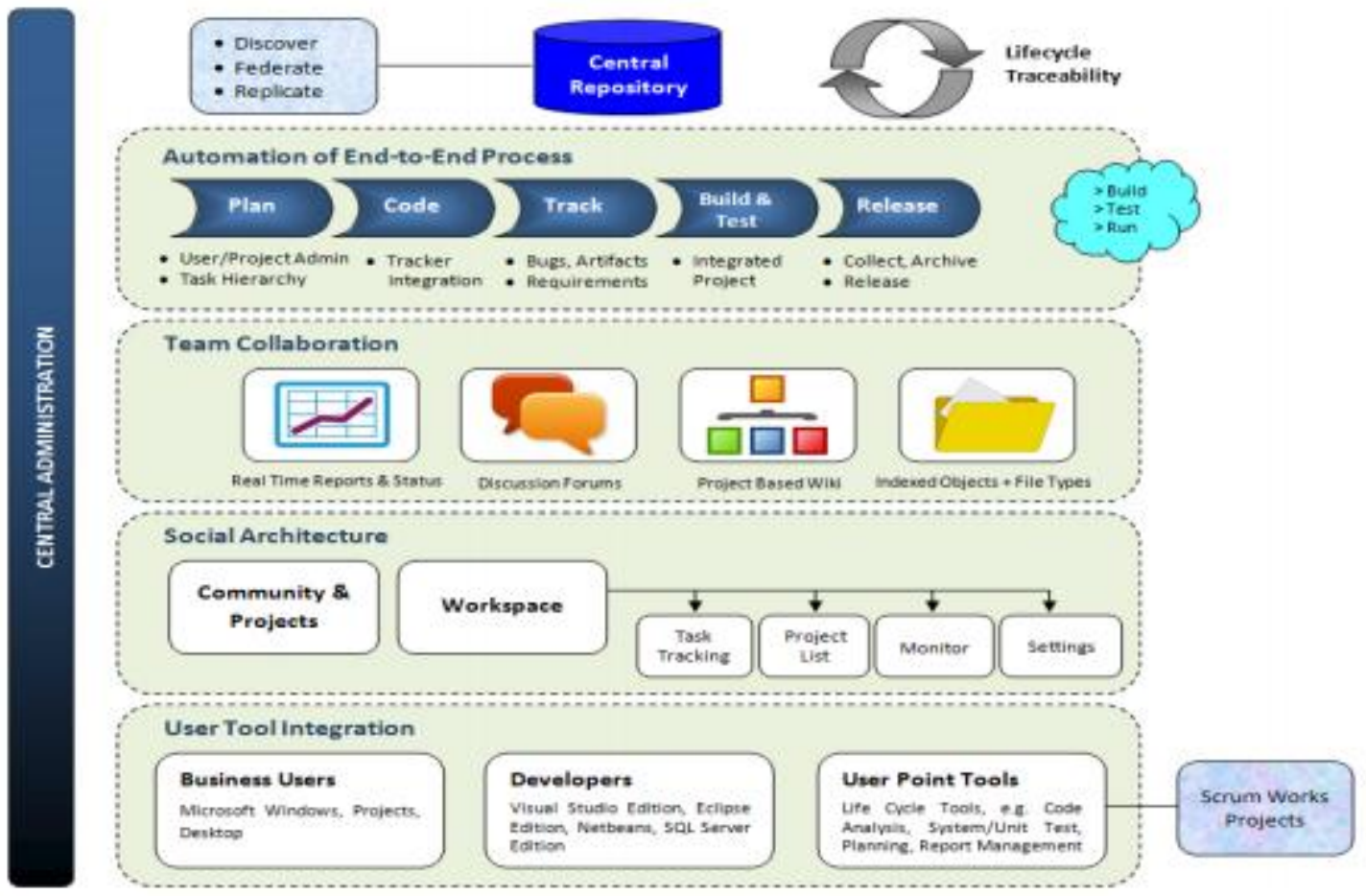

Figure 2: Cloud Based Agile Application Development Lifecycle

Note: "A Capability Maturity Framework for Sustainable Information and Communication Technology. IEEE IT Professional" Sheridan, C., \& Curry, E. (2011), 13(1), 33-40.

\section{REFERENCES}

[1] Ahola, J. et al. (2014). Handbook of the Secure Agile Software Development Life Cycle. Retrieved from, http://www.n4s.fi/2014magazine/article2/assets/guideboo k_handbook.pdf/ December 16, 2014

[2] Broberg, J., \& Brandic, I. (2009). Cloud computing and emerging IT platforms: Vision, hype, and reality for delivering computing as the 5th utility. Future Generation Computer Systems, 25(6), 599-616. Elsevier B.V

[3] Carcary M (2011) Design Science Research: The Case of the IT Capability Maturity Framework (IT CMF), the Electronic Journal of Business Research Methods, 9 (2), pp. 109-118

[4] Conway, G et al. (2014). Cloud Computing Adoption: An SME Case Study. Retrieved from, http://www.edwardcurry.org/publications/IAM_2014_S MECloudAdoption.pdf/

[5] Conway, G. \& Curry, E. (2012). Managing Cloud Computing: A Life Cycle Approach. Retrieved from, https://deri.ie/sites/default/files/publications/conway_clo udlifecycle_2012.pdf/

[6] Kaufman, L. M. (2009). Data Security in the World of Cloud Computing, IEEE Security and Privacy, vol. 7, no. 4, pp. 61-64

[7] Kecskemeti, K. \& Brandic, G. (2009). An SLA-based resource virtualization approach for on demand service provision. In Proceedings of the 3rd international workshop on Virtualization technologies in distributed

[8] Khan, A. R. et al. (2011). Service-Oriented Architecture for Collaborative Web Based Project Management Software. Retrieved from, http://ijngca.com/DrARK/aicera/Service-

Oriented $\% 20$ Architecture $\% 20$ for $\% 20$ Collaborative $\% 20$ Web\%20Based\%20Project\%20Management\%20Softwar e1.pdf/ December 16, 2014

[9] Murphy, E. T. \& Duggan, J. (2012). Magic Quadrant for Application Life Cycle Management. Retrieved from, http://www.techostan.com/docs/quadrant.pdf/

[10] Nazir, A., Raana, A. \& Khan, M. F. (2013). Cloud Computing ensembles Agile Development Methodologies for Successful Project Development. Retrieved from, http://www.mecspress.org/ijmecs/ijmecs-v5-n11/IJMECS-V5-N11-4.pdf/

[11] Phil F. \& Brian F. (2007). Delivering SOA solutions: service lifecycle management. Retrieved from, http://www.meritalk.com/uploads_legacy/whitepapers/IB M_15825_Delivering_SOA_solutions.pdf/ December 16, 2014

[12] Sheridan, C., \& Curry, E. (2011). A Capability Maturity Framework for Sustainable Information and Communication Technology. IEEE IT Professional, 13(1), 33-40

[13] Yang, H., \& Tate, M. (2009). Where are we at with Cloud Computing? A Descriptive Literature Review, 20th Australasian Conference on Information Systems; 2-4 Dec 2009 